\title{
REM-associated sleep apnoea: prevalence and clinical significance in the HypnoLaus cohort
}

\author{
Patricia Acosta-Castro ${ }^{1,2,6}$, Camila Hirotsu ${ }^{1,6}$, Helena Marti-Soler ${ }^{3}$, \\ Pedro Marques-Vidal ${ }^{4}$, Nadia Tobback ${ }^{1}$, Daniela Andries ${ }^{1}$, Gérard Waeber $^{4}$, \\ Martin Preisig ${ }^{5}$, Peter Vollenweider ${ }^{4}$, José Haba-Rubio ${ }^{1,7}$ and \\ Raphael Heinzer ${ }^{1,7}$
}

Affiliations: ${ }^{1}$ Center for Investigation and Research in Sleep (CIRS), University Hospital of Lausanne, Lausanne, Switzerland. ${ }^{2}$ Pulmonary Dept, University Hospital Ramon y Cajal, Madrid, Spain. ${ }^{3}$ Institute of Social and Preventive Medicine, University Hospital of Lausanne, Lausanne, Switzerland. ${ }^{4}$ Dept of Internal Medicine, University Hospital of Lausanne, Lausanne, Switzerland. ${ }^{5}$ Psychiatry Dept, University Hospital of Lausanne, Lausanne, Switzerland. ${ }^{6} \mathrm{P}$. Acosta-Castro and C. Hirotsu contributed equally to this study as cofirst authors. ${ }^{7} \mathrm{~J}$. Haba-Rubio and R. Heinzer contributed equally to this study as co-last authors.

Correspondence: Raphael Heinzer, Center for Investigation and Research in Sleep, Pulmonary Dept, University Hospital of Lausanne and Lausanne University, 1011 Lausanne, Switzerland.

E-mail: raphael.heinzerachuv.ch

@ERSpublications

REM sleep-disordered breathing is highly prevalent and is associated with metabolic syndrome and diabetes http://ow.ly/u52H30kBh3u

Cite this article as: Acosta-Castro P, Hirotsu C, Marti-Soler H, et al. REM-associated sleep apnoea: prevalence and clinical significance in the HypnoLaus cohort. Eur Respir J 2018; 52: 1702484 [https://doi. org/10.1183/13993003.02484-2017].

ABSTRACT This study determined the prevalence of rapid eye movement (REM) related sleepdisordered breathing (REM-SDB) in the general population and investigated the associations of REM-SDB with hypertension, metabolic syndrome, diabetes and depression.

Home polysomnography (PSG) recordings $(n=2074)$ from the population-based HypnoLaus Sleep Cohort (48.3\% men, $57 \pm 11$ years old) were analysed. The apnoea-hypopnoea index was measured during REM and non-REM sleep (as REM-AHI and NREM-AHI, respectively). Regression models were used to explore the associations between REM-SDB and hypertension, diabetes, metabolic syndrome and depression in the entire cohort and in subgroups with NREM-AHI $<10$ events $^{-1} \mathrm{~h}^{-1}$ and total AHI $<10$ events $\cdot h^{-1}$

The prevalence of REM-AHI $\geqslant 20$ events $\cdot \mathrm{h}^{-1}$ was $40.8 \%$ in the entire cohort. An association between increasing REM-AHI and metabolic syndrome was found in the entire cohort and in both the NREM-AHI and AHI subgroups ( $p$-trend $=0.014,<0.0001$ and 0.015 , respectively). An association was also found between REM-AHI $\geqslant 20$ events. $\mathrm{h}^{-1}$ and diabetes in both the NREM-AHI $<10$ events. $\mathrm{h}^{-1}$ (odds ratio (OR) 3.12 (95\% CI 1.35-7.20)) and AHI <10 events.h ${ }^{-1}$ (OR 2.92 (95\% CI 1.12-7.63)) subgroups. Systolic and diastolic blood pressure were positively associated with REM-AHI $\geqslant 20$ events $\cdot h^{-1}$.

REM-SDB is highly prevalent in our middle-to-older age sample and is independently associated with metabolic syndrome and diabetes. These findings suggest that an increase in REM-AHI could be clinically relevant.

This article has supplementary material available from erj.ersjournals.com

Received: Dec 072017 | Accepted after revision: June 192018

Copyright OERS 2018 


\section{Introduction}

Sleep-disordered breathing (SDB) is highly prevalent in the general population [1], causing intermittent hypoxaemia, microarousals, sleep fragmentation, and acute changes in blood pressure (BP) and heart rate. SDB during rapid eye movement (REM) sleep (REM-SDB) is estimated to occur in 10-36\% of patients with SDB [2], but its prevalence in the general population is not yet known.

REM-SDB is more common in patients with mild and moderate SDB [3] and has a higher prevalence in younger women than in men [4]. Data about sleepiness and REM-SDB are conflicting, but studies found no association between REM-SDB and daytime sleepiness or reduced quality of life [5-8].

Nocturnal respiratory events are usually more frequent and of longer duration in REM sleep compared with non-REM (NREM) sleep, probably due to greater pharyngeal muscle relaxation [9-11] and a reduction in the hypoxic and hypercapnic ventilatory response throughout REM sleep [12, 13].

Along with intermittent hypoxia, elevated sympathetic activity is thought to be the most important mechanism underlying the increased cardiovascular risk associated with SDB [14]. Compared with NREM sleep, REM sleep is associated with higher sympathetic activity and cardiovascular instability [15-17]. Recent studies have shown an association between REM-SDB and non-dipping nocturnal BP and hypertension [18-20]. Furthermore, REM-SDB has been reported to have an adverse effect on long-term glycaemic control and insulin resistance $[21,22]$. However, the specific impact of REM-SDB on cardiovascular risk factors and psychiatric comorbidities is not yet known.

This study evaluated the prevalence of REM-SDB in the general population and investigated the associations between REM-SDB and cardiovascular, metabolic and psychiatric comorbidities.

\section{Methods}

Population sample

The HypnoLaus Sleep Cohort study has been described previously [1]. It included a random subset of the population-based CoLaus/PsyCoLaus cohort $[23,24]$ who underwent full polysomnography (PSG) at home and answered questionnaires about their sleep complaints, including the Epworth Sleepiness Scale (ESS) [25]. The ethics committee of the University of Lausanne approved the CoLaus/PsyCoLaus cohort study and the HypnoLaus Sleep Cohort study. Written informed consent was obtained from all participants.

\section{Sleep data analysis}

PSG was performed by certified technicians who equipped participants with a polysomnographic recorder (Titanium, Embla Flaga, Reykjavik, Iceland) in accordance with the 2007 American Academy of Sleep Medicine (AASM) recommended setup specifications [26] at the Center for Investigation and Research in Sleep (CIRS) at the University Hospital of Lausanne. All PSGs took place in the patients' home environment. Sleep stages were scored in 30-s epoch according to the 2007 AASM criteria. Apnoeas, hypopnoeas and respiratory effort related arousals were scored according to the 2012 AASM criteria [27].

The average number of apnoeas-hypopnoeas per hour of sleep (the apnoea-hypopnoea index (AHI)) was calculated for the whole night and for REM and NREM sleep separately. The percentage of total sleep time (TST) with oxygen saturation below $90 \%$ (T90) and the number of $3 \%$ or greater oxygen desaturations per hour (the oxygen desaturation index (ODI)) were assessed.

Quality control for concordance between the two PSG scorers was implemented periodically to ensure that both achieved at least $90 \%$ agreement for sleep stages and respiratory events, and $85 \%$ agreement for arousals. An expert sleep clinician reviewed every recording and a second sleep expert performed quality checks. We asked individuals who were currently receiving treatment for SDB $(n=38)$ to discontinue their treatment 1 week before the sleep recording.

\section{Outcome variables}

Body weight and height were measured with participants standing without shoes in light indoor clothes. Body weight was measured in kilograms to the nearest $100 \mathrm{~g}$ using a Seca scale (Seca, Hamburg, Germany), which was calibrated regularly. Height was measured to the nearest $5 \mathrm{~mm}$ using a Seca height gauge. Body mass index (BMI) was calculated as weight $(\mathrm{kg}) /$ height $\left(\mathrm{m}^{2}\right)$.

Waist was measured with a non-stretchable tape over the unclothed abdomen at the narrowest point between the lowest rib and the iliac crest, while hip was measured at the largest part of the hips. Two measures were made for waist and hip and the mean (expressed in centimetres) was used to assess the waist-to-hip ratio (WHR). Neck circumference was measured at the middle of the neck between the mid-cervical spine and the superior line of the cricothyroid membrane. 
BP was measured three times on the left arm in the morning and the average of the last two readings was considered. Arterial hypertension was defined as systolic BP $\geqslant 140 \mathrm{mmHg}$, diastolic BP $\geqslant 90 \mathrm{mmHg}$, or current use of antihypertensive drugs. Diabetes was defined as fasting blood glucose $\geqslant 7 \mathrm{mmol} \cdot \mathrm{L}^{-1}$ or current antidiabetic drug treatment. Metabolic syndrome was defined according to the Adult Treatment Panel III (ATP-III) report [28]. Smoking status, alcohol consumption and the number of alcoholic drinks taken before the PSG recording and weekly were self-reported. The semi-structured Diagnostic Interview for Genetic Studies (DIGS) was used to diagnose current major depressive disorder, which was defined according to criteria of the Diagnostic and Statistical Manual of Mental Disorders, 4th edition (DSM-IV) [29]. Interviewers were required to be masters-level psychologists and were trained over a two-month period. During data collection, each interview was reviewed by an experienced senior clinical psychologist. The DIGS interview systematically assesses the last and the most severe depressive episodes.

\section{Statistical analysis}

All statistical analyses were performed with IBM SPSS version 21.0 (IBM Corp, Armonk, NY, USA). Bivariate analyses were performed using the Chi-squared test for categorical variables and the KruskalWallis test for continuous variables. Pairwise comparisons were performed using the Mann-Whitney test with Bonferroni's correction for p-value. Logistic regression models were used to estimate the association between REM-SDB and the presence of hypertension, diabetes, metabolic syndrome and depression.

The AHI during REM sleep (REM-AHI) was classified into four severity categories (REM-AHI $<5$ events $\cdot \mathrm{h}^{-1}$ (reference group), 5-9.9 events $\cdot \mathrm{h}^{-1}, 10-19.9$ events $\cdot \mathrm{h}^{-1}$ and $\geqslant 20$ events $\cdot \mathrm{h}^{-1}$ ) for the primary analysis (according to previous results of the HypnoLaus cohort) and used as a continuous variable for sensitivity analysis. A linear regression model was also used to assess the association between REM-AHI (as a continuous and a dummy variable) and diastolic and systolic BP.

Analyses were performed on the entire cohort and in two subgroups: one restricted to subjects with a total AHI $<10$ events $h^{-1}$ (absent or mild SDB) and another in those with AHI in NREM sleep (NREM-AHI) $<10$ events $\mathrm{h}^{-1}$ (exclusive REM-SDB). For hypertension, diabetes and metabolic syndrome, the models were adjusted for age, sex, BMI, WHR, TST, logarithm of NREM-AHI (log-NREM-AHI), smoking and alcohol consumption. An additional adjustment for antihypertensive treatment was added when systolic BP and diastolic BP were used as outcome variables in the linear regression models. For depression, the model was adjusted for age, sex, and consumption of benzodiazepines and antidepressants. Results were expressed as odds ratios (ORs) with $95 \%$ CIs. Statistical significance was considered as $\mathrm{p}<0.05$ for a two-sided test and as $\mathrm{p}<0.008$ for multiple comparisons in univariate analysis.

\section{Results}

\section{Study population}

Of the 2168 subjects ( $48.3 \%$ men; $59 \pm 11$ years old (range $40-85$ ); BMI $25.6 \pm 4.1 \mathrm{~kg} \cdot \mathrm{m}^{-2}$ ) who underwent complete PSG at home, 60 (3\%) had technical problems, 54 underwent a second recording and six subjects refused resulting in 2162 valid PSG recordings. Of these, 41 subjects with less than $4 \mathrm{~h}$ of TST were excluded to avoid the risk of unbalanced representation of different sleep stages. In addition, a further 47 patients with less than 30 min of REM sleep were excluded to allow a proper assessment of REM sleep [18, 19]. Therefore, 2074 PSG recordings were included in the analysis. Clinical and polysomnographic characteristics of the total sample are shown in table 1.

\section{REM-SDB in the entire cohort}

The overall prevalence of moderate-to-severe REM-SDB (REM-AHI $\geqslant 20$ events $\cdot \mathrm{h}^{-1}$ ) was $40.8 \%$ in the HypnoLaus middle-to-older age general population sample. As REM-AHI increased there was a corresponding increase in mean age, BMI, WHR and neck circumference, as well as in the prevalence of hypertension, diabetes and metabolic syndrome (table 1). Patients in the higher REM-AHI severity categories had lower TST and lower proportions of slow wave sleep (SWS) and REM sleep. They also had higher ODIs and arousal indices and spent more time with oxygen saturation at less than $90 \%$ (higher T90); however, there was no difference between the ESS scores for the REM-SDB severity categories. The results for the association of REM-SDB with metabolic syndrome, diabetes, hypertension and depression are shown in figure 1.

The REM-AHI categories of 5-9.9 events $\cdot \mathrm{h}^{-1}$ (OR 1.78 (1.13-2.81), $\mathrm{p}=0.013$ ), 10-19.9 events $\cdot \mathrm{h}^{-1}$ (OR 1.69 $(1.12-2.57), \mathrm{p}=0.013)$ and $\geqslant 20$ events $\mathrm{h}^{-1}$ (OR $\left.1.94(1.29-2.92), \mathrm{p}=0.001\right)$ were independently associated with metabolic syndrome but not diabetes or depression. Although we found no association between hypertension and REM-SDB, there was a significant association of REM-AHI $\geqslant 20$ events $\mathrm{h}^{-1}$ with both systolic and diastolic BP (table 2). 
TABLE 1 Subject characteristics in the entire cohort based on rapid eye movement (REM) apnoea-hypopnoea index (AHI) severity (REM-AHI severity)

REM-AHI severity categories in the entire cohort

\begin{tabular}{|c|c|c|c|c|c|}
\hline All & $<5$ events $\cdot h^{-1}$ & $5-9.9$ events $\cdot \mathrm{h}^{-1}$ & $\begin{array}{l}10-19.9 \\
\text { events } \cdot h^{-1}\end{array}$ & $\geqslant 20$ events $\cdot \mathrm{h}^{-1}$ & p-value \\
\hline 2074 (100) & $456(22.0)$ & $331(16.0)$ & 441 (21.3) & $846(40.8)$ & \\
\hline 1079 (52.0) & $318(69.7)^{\#}$ & $189(57.1)^{\#}$ & $220(49.9)$ & $352(41.6)$ & $<0.0001$ \\
\hline $56.3(48.5-66.2)$ & $51.3(45.6-59.6)$ & $54.1(47.0-63.1)^{\#}$ & $55.9(48.9-65.7)^{\#}$ & $60.6(52.5-68.4)^{\#, 9,+}$ & $<0.0001$ \\
\hline 25.7 (23.2-28.5) & $23.7(21.5-26.3)$ & $24.2(22.1-26.5)$ & $25.6(23.3-27.9)^{\#,+}$ & $27.4(25.0-30.4)^{\#, \Upsilon_{1,+}}$ & $<0.0001$ \\
\hline $0.92(0.87-0.97)$ & $0.89(0.84-0.94)$ & $0.90(0.85-0.95)$ & $0.91(0.87-0.97)^{\#,+}$ & $0.94(0.90-0.98)^{\#, 9,+}$ & $<0.0001$ \\
\hline $37.0(33.5-39.8)$ & $34.0(32.0-37.5)$ & $35.0(33.0-38.5)$ & $37.0(34.0-39.0)^{\#,+}$ & $38.0(35.0-41.0)^{\#, \uparrow,+}$ & $<0.0001$ \\
\hline $846(40.8)$ & $111(24.3)$ & $115(34.7)$ & $165(37.4)$ & $455(53.9)^{\#}$ & $<0.0001$ \\
\hline 200 (9.7) & 15 (3.3) & $18(5.4)$ & $30(6.8)$ & $137(16.2)^{\#}$ & $<0.0001$ \\
\hline $623(30.0)$ & 56 (12.3) & 64 (19.3) & $120(27.2)$ & $383(45.3)$ & $<0.0001$ \\
\hline $107(6.2)$ & $23(6.3)$ & $13(4.6)$ & $25(6.6)$ & $46(6.6)$ & 0.668 \\
\hline 532 (25.7) & 66 (14.5) & 66 (19.9) & 95 (21.5) & $305(36.1)^{\#}$ & $<0.0001$ \\
\hline $115(5.7)$ & $31(7.1)$ & $11(3.4)$ & $20(4.6)$ & $53(6.4)$ & 0.096 \\
\hline $171(8.4)$ & $33(7.4)$ & $28(8.5)$ & $35(8.1)$ & 75 (8.9) & 0.815 \\
\hline 379 (18.5) & 92 (20.3) & $60(18.3)$ & $78(17.8)$ & 149 (17.9) & 0.063 \\
\hline $0.45 \pm 0.89$ & $0.42 \pm 0.82$ & $0.43 \pm 0.82$ & $0.40 \pm 0.88$ & $0.49 \pm 0.93$ & 0.276 \\
\hline $6.5 \pm 7.9$ & $5.5 \pm 7.2$ & $5.8 \pm 6.9$ & $6.7 \pm 8.2$ & $7.1 \pm 8.4^{\#}$ & 0.007 \\
\hline $\begin{array}{c}406.5(364.0- \\
449.6)\end{array}$ & $\begin{array}{c}409.2(370.6- \\
453.5)\end{array}$ & $\begin{array}{c}411.5(370.5- \\
454.0)\end{array}$ & $\begin{array}{c}415.0(367.3- \\
457.3)\end{array}$ & $\begin{array}{c}397.5(353.9- \\
441.5)^{\#, 91,+}\end{array}$ & $<0.0001$ \\
\hline $\begin{array}{c}120.4(53.4- \\
196.1)\end{array}$ & $105.4(49.0-174.3)$ & $\begin{array}{c}125.6(62.5- \\
194.6)^{\#}\end{array}$ & 127.5 (58.4-187.0) & $122.6(49.6-209.3)$ & 0.040 \\
\hline $20.0(2.0-44.2)$ & $17.1(0-42.2)$ & $20.0(3.1-47.0)$ & $20.5(2.1-40.5)$ & $21.4(2.9-46.4)$ & 0.094 \\
\hline $22.5(18.6-26.1)$ & $23.6(19.9-27.0)$ & 23.0 (19.9-26.3) & $22.9(19.3-26.2)$ & $21.1(17.2-25.4)^{\#, \uparrow,+}$ & $<0.0001$ \\
\hline $19.4(14.2-25.0)$ & $20.8(16.3-25.8)$ & $20.0(15.3-25.6)$ & $19.8(14.3-25.7)$ & $18.0(12.5-23.9)^{\#, 9,+}$ & $<0.0001$ \\
\hline $18.7(13.8-25.9)$ & $14.2(10.4-19.7)^{\#}$ & $17.1(13.6-22.0)^{\#}$ & $18.1(14.1-23.8)^{\#}$ & $23.2(16.6-31.1)^{\#, 9,+}$ & $<0.0001$ \\
\hline $9.8(4.2-20.1)$ & $2.0(1.0-4.8)$ & $4.3(2.9-8.1)^{\#}$ & $9.0(6.0-13.5)^{\#,+}$ & $21.4(13.9-34.5)^{\#, \eta_{1,+}}$ & $<0.0001$ \\
\hline $7.4(2.3-17.2)$ & $1.7(0.6-5.0)$ & $3.4(1.4-7.8)^{\#}$ & $6.6(3.0-12.0)^{\#,+}$ & $16.6(8.3-30.1)^{\#, 9,++}$ & $<0.0001$ \\
\hline $15.3(5.7-30.3)$ & $2.2(0.9-3.4)$ & $7.1(6.0-8.6)^{\#}$ & $14.5(12.4-16.8)^{\#,+}$ & $34.4(25.7-46.8)^{\#, 9,+}$ & $<0.0001$ \\
\hline $8.8(2.6-23.0)$ & $1.3(0-2.7)$ & $5.1(2.2-7.3)^{\#}$ & $10.4(6.2-14.3)^{\#,+}$ & $26.7(18.2-40.9)^{\#, 9,+}$ & $<0.0001$ \\
\hline $27.9(8.4-52.7)$ & $2.7(0-6.2)$ & $10.8(7.0-23.4)^{\#}$ & $25.1(16.4-42.5)^{\#,+}$ & $52.2(37.5-68.6)^{\#, \eta_{1,+}}$ & $<0.0001$ \\
\hline $9.9(4.3-19.0)$ & $2.4(1.0-5.5)$ & $4.7(3.0-9.0)^{\#}$ & $8.7(5.6-14.3)^{\#,+}$ & $19.8(12.9-30.9)^{\#, 9,+}$ & $<0.0001$ \\
\hline $4.1 \pm 12.3$ & $7.2 \pm 1.1$ & $9.3 \pm 1.4^{\#}$ & $13.0 \pm 3.5^{\#,+}$ & $14.3 \pm 7.0^{\#, 9,+}$ & $<0.0001$ \\
\hline $6.0(3.0-9.0)$ & $6.0(3.0-8.0)$ & $5.0(3.0-9.0)$ & $6.0(3.8-8.0)$ & $6.0(3.0-9.0)$ & 0.690 \\
\hline
\end{tabular}

Subjects
Female
Age years
BMI $\mathrm{kg} \cdot \mathrm{m}^{-2}$
WHR
Neck circumference cm
Hypertension
Type 2 diabetes
Metabolic syndrome
Depression
Antihypertensive medication
Antidepressant medication
Benzodiazepines
Current smoking
Alcohol consumption before
PSG
Alcohol consumption weekly
TST min
TST in supine min
REM time in supine min
REM time \% of TST
SWS time \% of TST
Arousal index events $\cdot \mathrm{h}^{-1}$
Total AHI events $\mathrm{h}^{-1}$
NREM-AHI events $\mathrm{h}^{-1}$
REM-AHI events·
REM-AHI non-supine
events· $\mathrm{h}^{-1}$
REM-AHI supine events $\cdot \mathrm{h}^{-1}$
ODI $3 \%$ events $\cdot \mathrm{h}^{-1}$
T90 \% of TST
ESS score

Data are presented as $\mathrm{n}(\%)$, median (interquartile range) or mean $\pm \mathrm{SD}$, unless otherwise stated. Data was analysed by Pearson's Chi-squared test or the Kruskal-Wallis test followed by Mann-Whitney pairwise comparisons. The number of participants with missing data was as follows: alcohol consumption before PSG ( $n=31)$, antidepressant medication ( $n=49)$, benzodiazepines ( $n=27), B M I(n=12)$, smoking ( $n=22)$, depression $(n=353)$, diabetes $(n=2)$, hypertension $(n=2)$, neck circumference $(n=57), R E M-A H I$ non-supine $(n=89), R E M-A H I$ supine ( $n=394), R E M$ time in supine $(n=1), T 90(n=28)$, WHR ( $n=2)$. Values in bold indicate significant results ( $p<0.05)$. BMI: body mass index; WHR: waist-to-hip ratio; PSG: polysomnography; TST: total sleep time; NREM: non-rapid eye movement; SWS: slow wave sleep; ODI: oxygen desaturation index (number of $3 \%$ or greater oxygen desaturations per hour); T90: percentage of TST with oxygen saturation below 90\%; ESS: Epworth Sleepiness Scale. \#: $\mathrm{p}<0.008$ compared to $<5$ events $\cdot \mathrm{h}^{-1}$; ${ }^{\uparrow}$ : $\mathrm{p}<0.008$ compared to $10-19.9$ events $\cdot \mathrm{h}^{-1}{ }$; ${ }^{+}$: $\mathrm{p}<0.008$ compared to $5-9.9$ events $\cdot \mathrm{h}^{-1}$; ${ }^{\S}$ : alcohol consumption=mean consumption of standard drinks containing $10 \mathrm{~g}$ of alcohol.

\section{Exclusive REM-SDB}

A subgroup of 1241 subjects (59.8\%) with NREM-AHI $<10$ events. ${ }^{-1}$ was analysed to better define the specific influence of REM-SDB (table 3). In this subgroup, the prevalence of moderate-to-severe REM-SDB $\left(\right.$ REM-AHI $\geqslant 20$ events $\left.\cdot h^{-1}\right)$ was $21.2 \%(n=263)$. As in the overall analysis, patients in the highest REM-AHI severity categories were older and had higher BMI, WHR and neck circumference, as well as a higher prevalence of hypertension, diabetes and metabolic syndrome.

Values for TST and REM sleep time were reduced only in the REM-AHI $\geqslant 20$ events.h ${ }^{-1}$ group, while arousal index, ODI and T90 were increased in all REM-SDB subgroups. No significant differences in SWS time and ESS score were found amongst the REM-SDB severity categories.

The same multivariate models were applied to this subgroup (figure 2) and increasing REM-AHI severity was found to be significantly associated with metabolic syndrome and diabetes, while hypertension and 


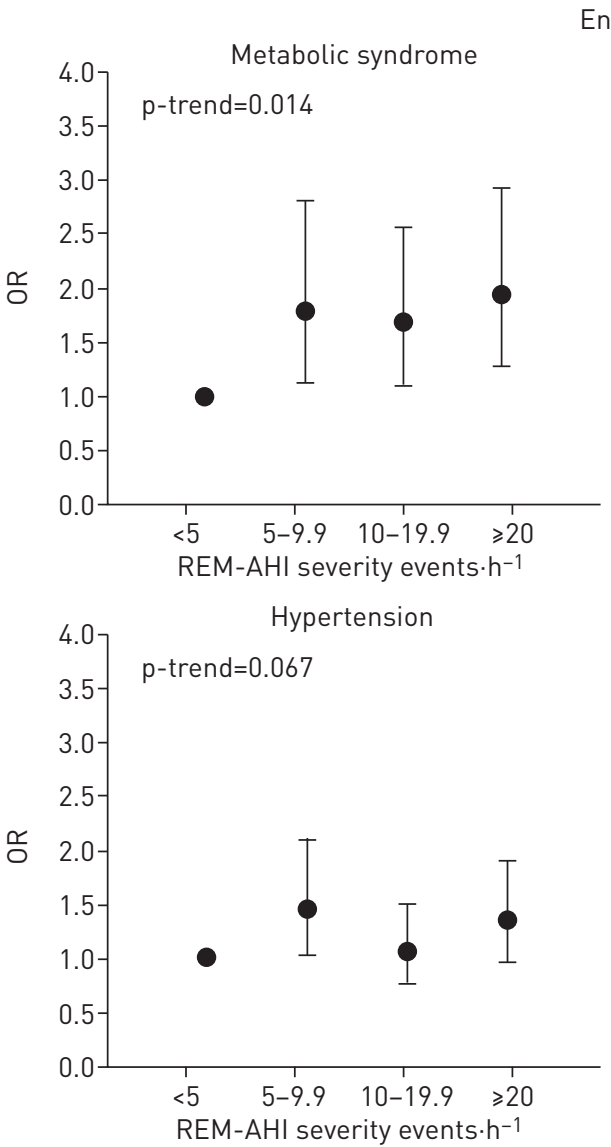

Entire cohort
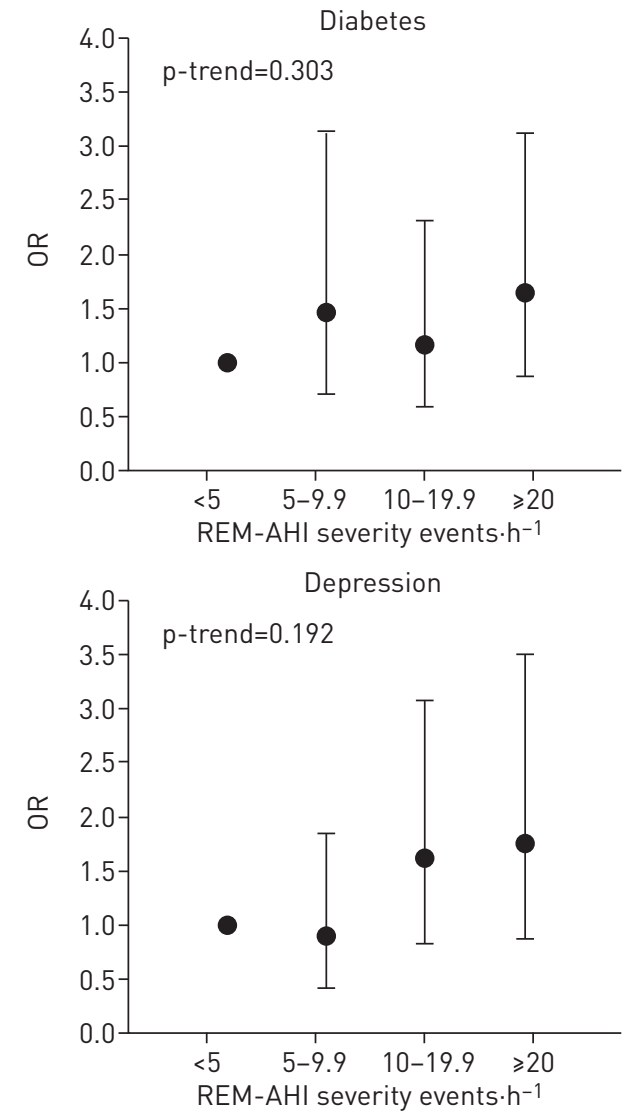

FIGURE 1 Odds ratios (ORs) and 95\% Cls for rapid eye movement (REM) apnoea-hypopnoea index (AHI) severity categories (REM-AHI severity) in the entire cohort ( $n=2074$ polysomnographies (PSGs)). Circles represent the ORs and bars represent the $95 \% \mathrm{Cls}$. Logistic regression models were fitted to examine the associations for the entire cohort with metabolic syndrome, diabetes, hypertension and depression. Increasing REM-AHI severity was significantly associated with metabolic syndrome. Hypertension, diabetes and depression were not significantly associated with REM related sleep-disordered breathing. Cardiovascular and metabolic comorbidities were adjusted for age, sex, body mass index, waist-to-hip ratio, total sleep time, smoking, alcohol consumption (weekly) and the logarithm of non-REM-AHI (log-NREM-AHI). Depression was adjusted for age, gender, consumption of benzodiazepines, antidepressants and log-NREM-AHI. The number of participants with missing data in the models was as follows: metabolic syndrome $(n=35)$, diabetes $(n=37)$, hypertension $(n=37)$, depression $(n=389)$.

depression showed no association with REM-SDB. Although the p-value for trend was not significant for depression, the subgroup with the highest severity of REM-SDB (i.e. REM-AHI $>20$ events $\cdot \mathrm{h}^{-1}$ ) had a trend towards higher odds of depression (OR $2.14(0.99-4.64), \mathrm{p}=0.054)$ when compared to the group with no REM-SDB (i.e. REM-AHI $<5$ events.h ${ }^{-1}$ ).

\section{Absent or mild SDB}

A second subgroup of 1047 subjects $(50.5 \%)$ with total AHI $<10$ events $\cdot \mathrm{h}^{-1}$ was analysed to evaluate the prevalence and significance of REM-SDB in subjects with absent or mild SDB (table 4). In this subgroup the prevalence of moderate-to-severe REM-SDB (REM-AHI $\geqslant 20$ events $\cdot h^{-1}$ ) was 9.1\% ( $n=95$ ). As observed in the exclusive REM-SDB subgroup and the overall population, increasing REM-AHI severity was associated in univariate analysis with higher mean age, BMI, WHR and neck circumference, as well as a higher prevalence of metabolic syndrome, diabetes and hypertension.

Only the REM-AHI $\geqslant 20$ events $\mathrm{h}^{-1}$ group presented lower TST and REM sleep time compared to the other groups, while all REM-SDB subgroups presented increased arousal index compared to the REM-AHI $<5$ events.h ${ }^{-1}$ group. Subjects with higher REM-AHI showed increased ODI and T90; however, no significant differences in SWS time and ESS score were found across the REM-AHI categories.

The results of the logistic regression models applied to this subgroup are shown in figure 3 . There was a significant association of moderate-to-severe REM-SDB with both metabolic syndrome and diabetes, but not with hypertension or depression. 
TABLE 2 Associations between rapid eye movement apnoea-hypopnoea index (REM-AHI) and blood pressure (BP)

\begin{tabular}{|c|c|c|c|c|c|c|}
\hline & \multicolumn{2}{|c|}{ Entire cohort } & \multicolumn{2}{|c|}{$\begin{array}{c}\text { NREM-AHI }<10 \\
\text { events } \cdot \mathrm{h}^{-1} \text { subgroup } \\
\end{array}$} & \multicolumn{2}{|c|}{$\begin{array}{c}\mathrm{AHI}<10 \text { events } \cdot \mathrm{h}^{-1} \\
\text { subgroup }\end{array}$} \\
\hline & $\boldsymbol{\beta}$ & $p$-value & $\boldsymbol{\beta}$ & p-value & $\boldsymbol{\beta}$ & p-value \\
\hline \multicolumn{7}{|l|}{ Systolic BP } \\
\hline REM-AHI (continuous) & 0.03 & 0.167 & 0.01 & 0.842 & -0.03 & 0.671 \\
\hline $5-9.9$ events $\cdot h^{-1}$ & 2.02 & 0.070 & 1.28 & 0.275 & 1.43 & 0.213 \\
\hline $10-19.9$ events $\cdot \mathrm{h}^{-1}$ & 2.11 & 0.051 & 1.80 & 0.135 & 1.61 & 0.181 \\
\hline$\geqslant 20$ events $\cdot \mathrm{h}^{-1}$ & 2.40 & 0.030 & 0.50 & 0.701 & -1.18 & 0.486 \\
\hline \multicolumn{7}{|l|}{ Diastolic BP } \\
\hline REM-AHI (continuous) & 0.02 & 0.208 & 0.01 & 0.821 & -0.02 & 0.636 \\
\hline $5-9.9$ events $\cdot \mathrm{h}^{-1}$ & 1.27 & 0.089 & 1.01 & 0.193 & 1.02 & 0.179 \\
\hline $10-19.9$ events $\cdot \mathrm{h}^{-1}$ & 1.20 & 0.097 & 1.12 & 0.159 & 0.90 & 0.255 \\
\hline$\geqslant 20$ events $\cdot \mathrm{h}^{-1}$ & 1.72 & 0.020 & 0.23 & 0.787 & -1.19 & 0.289 \\
\hline
\end{tabular}

Data was analysed by linear regression using REM-AHI as a continuous or dummy variable with adjustment for age, sex, body mass index, waist-to-hip ratio, total sleep time, smoking, alcohol consumption (weekly), antihypertensive drug use and logarithm of NREM-AHI. The number of participants with missing data in the models (for the entire cohort, NREM-AHI $<10$ events $\cdot h^{-1}$ subgroup and the $A H I$ $<10$ events $\cdot h^{-1}$ subgroup) was as follows: systolic BP and diastolic BP $(n=16, n=6, n=5)$. Values in bold indicate significant results $(p<0.05)$. $\beta$ : linear regression coefficient beta; NREM: non-rapid eye movement.

We performed the same analysis using REM-AHI as a continuous variable instead of REM-AHI categories and with the same covariables as previously described. Using these models, we found significant associations between REM-AHI and metabolic syndrome in the entire cohort and the two subgroups, and with diabetes in both the NREM-AHI $<10$ events $\cdot \mathrm{h}^{-1}$ and AHI $<10$ events $\mathrm{h}^{-1}$ subgroups (see supplementary table S1). However, no association was significant for hypertension or depression.

\section{Discussion}

To our knowledge, this is the first study demonstrating an independent association of REM-SDB with metabolic syndrome and diabetes in the general population. We also showed in this analysis that the prevalence of moderate-to-severe REM-SDB (REM-AHI $\geqslant 20$ events $\mathrm{h}^{-1}$ ) in this middle-to-older age general population sample was $40.6 \%$ and that nearly $10 \%$ of patients with a global AHI of $<10$ events.h $\mathrm{h}^{-1}$ have moderate-to-severe REM-SDB. These findings may have important implications for routine clinical practice in sleep medicine because they suggest that REM-AHI may need to be considered independently from global AHI when interpreting PSG results in patients at risk for metabolic dysfunction.

\section{REM-SDB and metabolic syndrome}

Several studies have shown a relationship between SDB and metabolic syndrome [1,30,31], but none of them assessed the relationship with REM-SDB. In the present study, there was a clear and independent association between increasing REM-AHI severity and the presence of metabolic syndrome. This association was found in the whole sample as well as in subjects with absent or mild SDB (AHI $<10$ events $\cdot \mathrm{h}^{-1}$ ) and in those with exclusive REM-SDB (NREM-AHI $<10$ events $\cdot \mathrm{h}^{-1}$ ). This suggests that apnoeas and hypopnoeas occurring during REM sleep may have a specific association with metabolic syndrome.

\section{REM-SDB and diabetes}

Previous studies showed an association between REM-AHI severity and increasing levels of glycosylated haemoglobin (HbA1c) in patients with Type 2 diabetes and with insulin resistance $[21,22]$. In the present study we found a significant and independent association between diabetes and REM-SDB in both subgroups with NREM-AHI $<10$ events $\cdot h^{-1}$ and AHI $<10$ events.h ${ }^{-1}$. Recently, MOKHLESI et al. [32] described an improvement in glycaemic control in patients with Type 2 diabetes and SDB after 1 week of 8-h nightly continuous positive airway pressure (CPAP) treatment. However, another study, in which CPAP was used for a mean of $4.3 \mathrm{~h}$ per night, showed no significant improvement in glycaemic control in patients with Type 2 diabetes and SDB [33]. The better results obtained by MoKHLESI et al. [32] could be related to the longer duration of CPAP usage resulting in better control of REM-SDB, as REM sleep mainly occurs toward the end of the night. We can thus speculate that the negative results reported by previous studies with shorter CPAP usage (usually limited to the first hours of the night) may be due to 
TABLE 3 Patient characteristics in the non-rapid eye movement (NREM) apnoea-hypopnoea index (AHI) subgroup (NREM-AHI $<10$ events $\cdot h^{-1}$ ) based on rapid eye movement (REM)-AHI severity (REM-AHI severity)

REM-AHI severity categories in the NREM-AHI $<10$ events $\cdot \mathrm{h}^{-1}$ subgroup

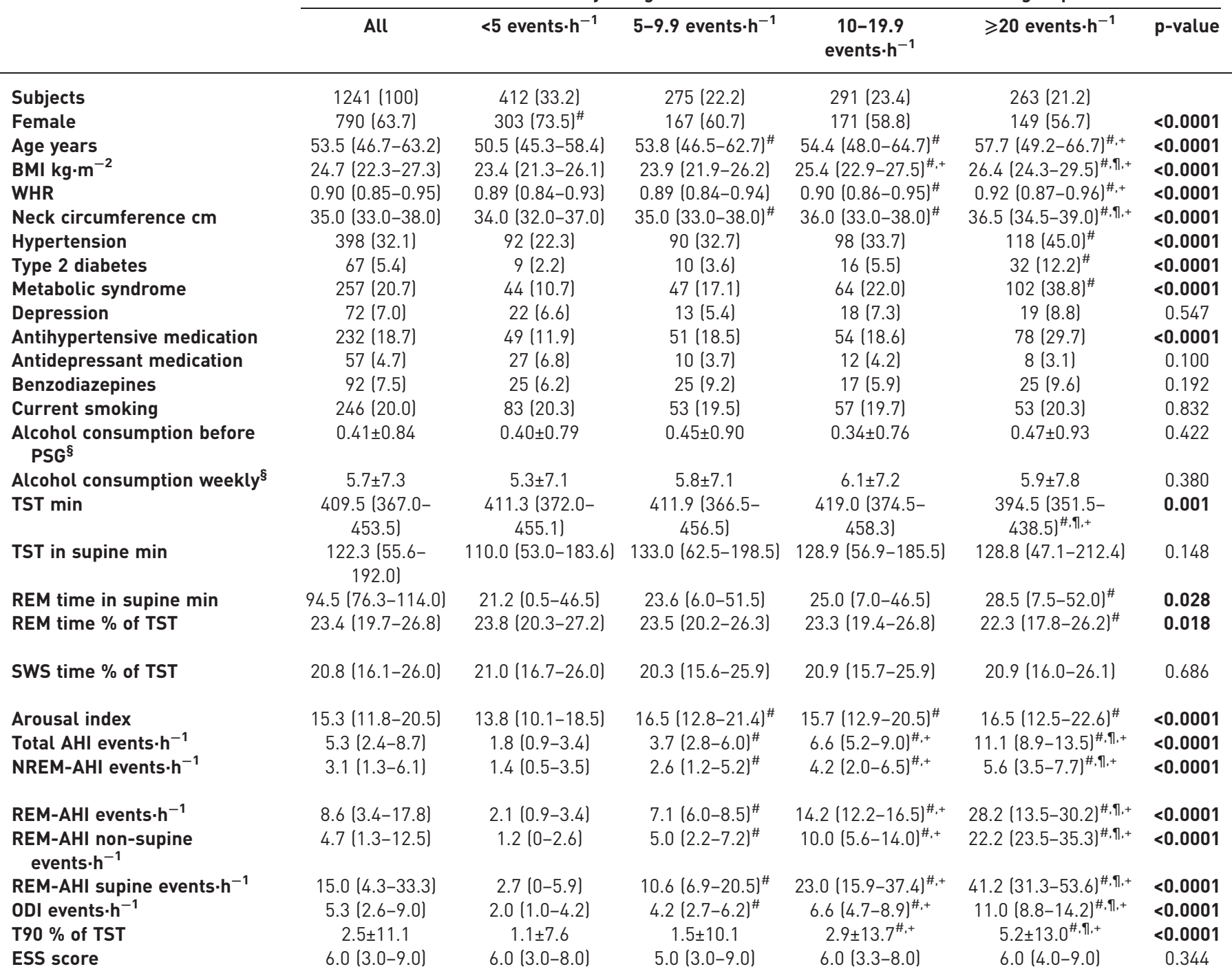

Data are presented as $\mathrm{n}(\%)$, median (interquartile range) or mean $\pm \mathrm{SD}$, unless otherwise stated. Data was analysed by Pearson's Chi-squared test or by the Kruskal-Wallis test, followed by Mann-Whitney pairwise comparisons. The number of participants with missing data was as follows: alcohol consumption before PSG $(n=20)$, antidepressant medication $(n=28)$, benzodiazepines $(n=16), B M I(n=3)$, smoking ( $n=9)$, depression ( $n=206)$, hypertension $(n=1)$, neck circumference $(n=35)$, REM-AHI non-supine $(n=44), R E M-A H I$ supine $(n=213), T 90$ ( $n=14)$, WHR $(n=1)$. Values in bold indicate significant results $(p<0.05)$. BMI: body mass index; WHR: waist-to-hip ratio; PSG: polysomnography; TST: total sleep time; SWS: slow wave sleep; ODI: oxygen desaturation index (number of 3\% or greater oxygen desaturations per hour); T90: percentage of TST with oxygen saturation below 90\%; ESS: Epworth Sleepiness Scale. ${ }^{\#}$ : $\mathrm{p}<0.008$ compared to $<5$ events $\cdot \mathrm{h}^{-1}$; ${ }^{\text {? }}$ : $\mathrm{p}<0.008$ compared to $10-$ 19.9 events $\cdot h^{-1} ;{ }^{+}: p<0.008$ compared to $5-9.9$ events $\cdot h^{-1} ;{ }^{\S}$ : alcohol consumption=mean consumption of standard drinks containing $10 \mathrm{~g}$ of alcohol.

insufficient treatment of REM-SDB in the second part of the night. The importance of longer nightly CPAP use was also recently suggested by the results of the SAVE study, where a significant decrease in cerebrovascular events in patients with moderate-to-severe sleep apnoea and coronary or cerebrovascular disease was present only in those who used CPAP for more than $4 \mathrm{~h}$ per night $[33,34]$. It is, however, unclear why this association was found mainly in the group with NREM-AHI $<10$ events. ${ }^{-1}$ in our study.

Different hypotheses can be proposed regarding the underlying mechanisms of the associations between REM-SDB and metabolic syndrome or diabetes. First, it is well established that respiratory events occurring during REM sleep have a longer duration and generate greater oxygen desaturations compared to NREM events [9-11]. This may trigger increased oxidative stress compared with other respiratory events, which could promote metabolic syndrome and diabetes. Acute intermittent hypoxia was also 


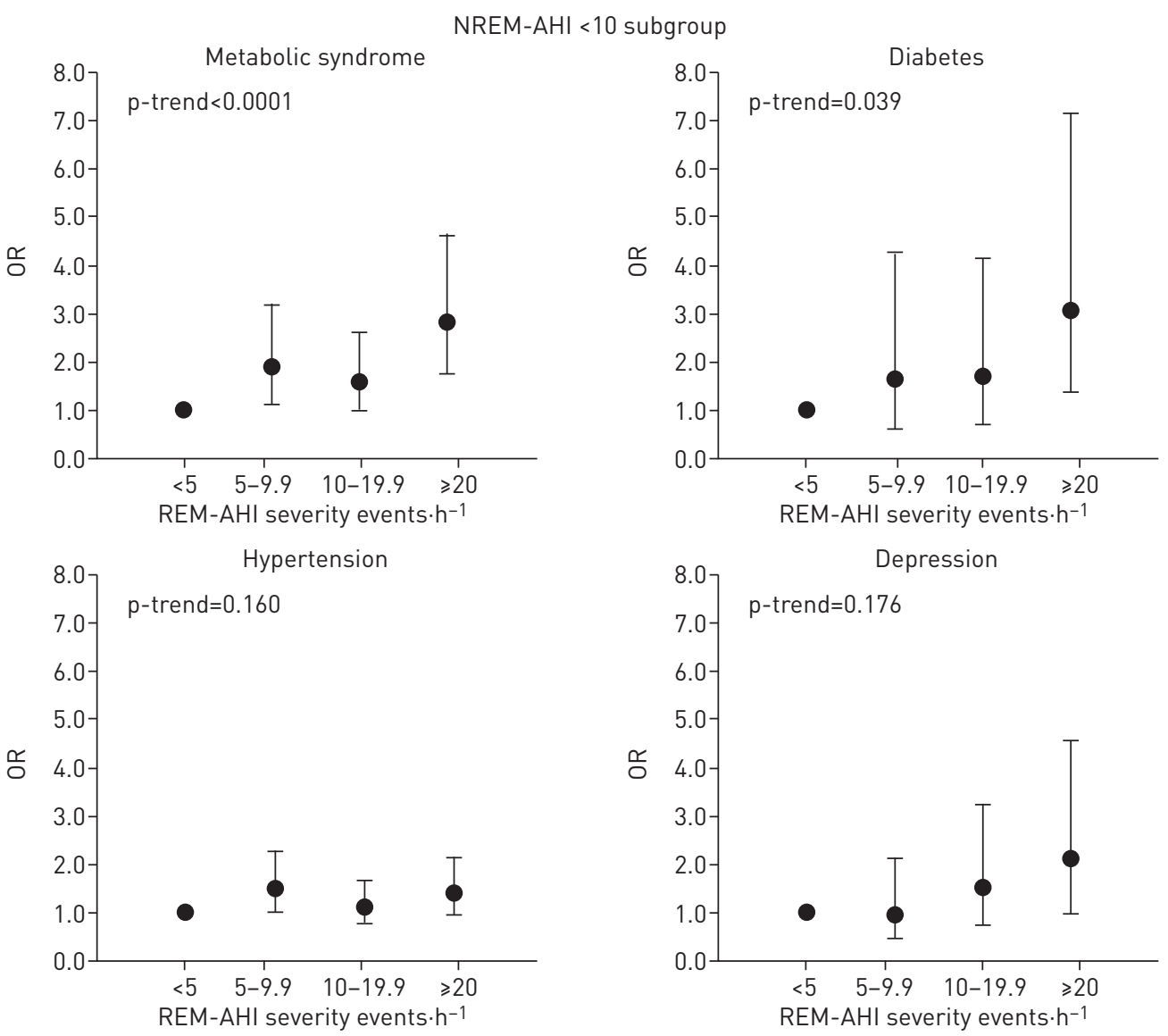

FIGURE 2 Odds ratios (ORs) and $95 \% \mathrm{Cls}$ for rapid eye movement (REM) apnoea-hypopnoea index (AHI) severity categories (REM-AHI severity) in the subgroup with non-REM-AHI (NREM-AHI) $<10$ events.h ${ }^{-1}$ $(n=1241$ polysomnographies (PSGs)). Circles represent the ORs and bars represent the $95 \%$ Cls. Logistic regression models were fitted to examine the associations for the entire cohort with metabolic syndrome, diabetes, hypertension and depression. Increasing REM-AHI severity was significantly associated with metabolic syndrome and diabetes. Hypertension and depression showed no association with REM related sleep-disordered breathing. Cardiovascular and metabolic comorbidities were adjusted for age, sex, body mass index, waist-to-hip ratio, total sleep time, smoking, alcohol consumption (weekly) and the logarithm of NREM-AHI (log-NREM-AHI). Depression was adjusted for age, gender, consumption of benzodiazepines, antidepressants and log-NREM-AHI. The number of participants with missing data in the models was as follows: metabolic syndrome ( $n=13)$, diabetes ( $n=13)$, hypertension ( $n=14)$, depression $(n=226)$.

shown to acutely increase insulin resistance in healthy volunteers [35]. In addition, compared to NREM sleep, sympathetic activity is greater during REM sleep and most endocrine organs implicated in glucose metabolism are sensitive to changes in sympathovagal balance [36-38]. Furthermore, SDB in REM reversed the physiological nocturnal decline of interstitial glucose concentration (IGC), while NREM-SDB had no effect on IGC [39]. Lastly, nocturnal hyperglycaemia associated with SDB in patients with diabetes was shown to be specifically accentuated during REM sleep [40].

\section{REM-SDB and hypertension}

We previously reported a significant association between SDB severity and hypertension in the population-based HypnoLaus sleep cohort [1]. Considering that two studies have shown a specific association between REM-SDB and increased incident hypertension [18, 19], we tested this association in our sample using a cross-sectional analysis. Surprisingly, there was no significant association between REM-SDB and hypertension in the whole sample, in the subgroups with REM-AHI $<10$ events.h ${ }^{-1}$ or global AHI $<10$ events $\cdot \mathrm{h}^{-1}$, nor in a subgroup without antihypertensive medication (supplementary table S2). The reason for the differences between our study and previous studies is unclear. In the Wisconsin cohort, the scoring of hypopnoeas required a $4 \%$ oxygen desaturation, which may have selected more severe respiratory events [41]. However, the MAILES study, which also found a significant association between REM-SDB and hypertension, used the currently recommended $3 \%$ criteria for scoring hypopnoeas [19]. Another difference is that the MAILES study included only males, whereas we included 
TABLE 4 Patient characteristics in the apnoea-hypopnoea index $(A H I)<10$ events $\cdot h^{-1}$ subgroup based on rapid eye movement (REM)-AHI severity (REM-AHI severity)

$\mathrm{REM}-\mathrm{AHI}$ severity categories in the $\mathrm{AHI}<10$ events $\cdot \mathrm{h}^{-1}$ subgroup

\begin{tabular}{|c|c|c|c|}
\hline All & $<5$ events $\cdot h^{-1}$ & $5-9.9$ events $\cdot h^{-1}$ & $\begin{array}{c}10-19.9 \\
\text { events}^{-1} h^{-1}\end{array}$ \\
\hline
\end{tabular}

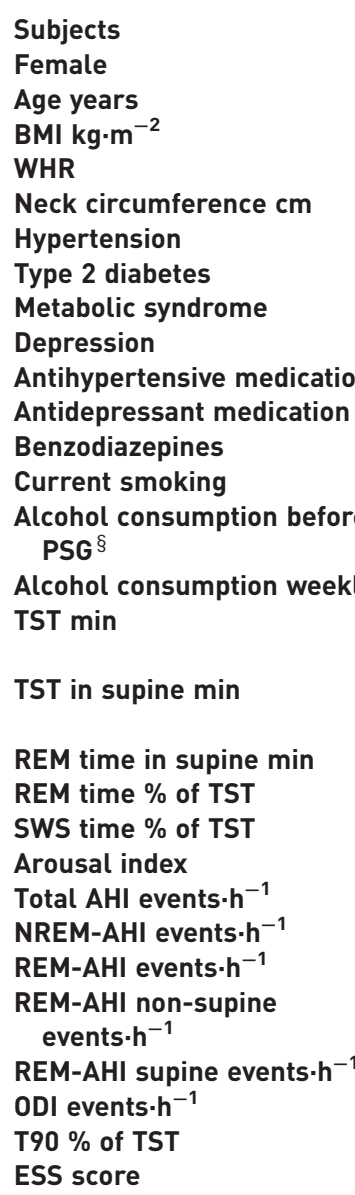

\begin{tabular}{|c|c|c|c|}
\hline 1047 (100) & $419(40)$ & 275 (26.3) & $258(24.6)$ \\
\hline 683 (65.2) & $305(72.8)^{\#}$ & $169(61.5)$ & 153 (59.3) \\
\hline $52.8(46.2-62.4)$ & $50.5(45.4-58.5)$ & $53.8(46.5-63.0)^{\#}$ & $54.4(48.0-64.3)^{\#}$ \\
\hline 24.3 (21.9-26.8) & $23.4(21.3-26.1)$ & $24.0(21.9-26.3)$ & $25.3(22.7-27.3)^{\#,+}$ \\
\hline $0.90(0.85-0.94)$ & $0.89(0.84-0.94)$ & $0.89(0.84-0.94)$ & $0.90(0.86-0.95)^{\#}$ \\
\hline 35.0 (33.0-38.0) & $34.0(32.0-37.0)^{\#}$ & $35.0(33.0-38.0)^{\#}$ & $35.5(33.0-38.0)^{\#}$ \\
\hline 312 (29.8) & $96(22.9)$ & $89(32.4)$ & $87(33.7)$ \\
\hline $45(4.3)$ & $10(2.4)$ & $10(3.6)$ & $14(5.4)$ \\
\hline $187(17.9)$ & 48 (11.5) & $47(17.1)$ & 55 (21.3) \\
\hline $56(6.4)$ & $22(6.5)$ & $13(5.4)$ & $16(7.2)$ \\
\hline $177(16.9)$ & $51(12.2)$ & 50 (18.2) & $49(19.0)$ \\
\hline $50(4.9)$ & $28(6.9)$ & $10(3.7)$ & $11(4.3)$ \\
\hline $79(7.7)$ & $25(6.1)$ & $25(9.2)$ & $16(6.3)$ \\
\hline $217(20.9)$ & $86(20.7)$ & $53(19.5)^{\#}$ & $56(21.8)^{\#}$ \\
\hline $0.40 \pm 0.81$ & $0.39 \pm 0.78$ & $0.45 \pm 0.90$ & $0.35 \pm 0.79$ \\
\hline $5.7 \pm 7.2$ & $5.4 \pm 7.3$ & $5.8 \pm 7.1$ & $6.0 \pm 7.3$ \\
\hline $\begin{array}{c}411.0 \text { (368.5- } \\
454.0)\end{array}$ & $\begin{array}{c}410.5(372.0- \\
455.5)\end{array}$ & $\begin{array}{c}411.5(366.5- \\
458.0)\end{array}$ & $\begin{array}{c}418.8 \text { (371.9- } \\
353.0 \text { ) }\end{array}$ \\
\hline $\begin{array}{c}121.2(55.4- \\
190.0)\end{array}$ & 109.9 (49.3-177.5) & $133.0(62.5-200.0)$ & 127.9 (54.3-187.0) \\
\hline $23.2(3.1-48.0)$ & $20.6(0.2-46.0)$ & $23.6(6.0-51.1)$ & $25.0(7.3-46.4)$ \\
\hline $23.3(19.7-26.6)$ & $23.8(20.3-27.2)$ & $23.5(20.2-26.3)$ & $23.2(19.4-26.6)$ \\
\hline 20.8 (16.3-25.9) & $20.9(16.6-25.9)$ & $20.1(15.6-25.9)$ & $20.6(15.6-25.9)$ \\
\hline $15.2(11.5-20.0)$ & $13.8(10.2-18.6)$ & $16.5(12.8-21.4)^{\#}$ & $15.5(12.8-20.1)^{\#}$ \\
\hline $4.2(2.1-6.9)$ & 1.8 (0.9-3.5) & $3.7(2.8-6.0)^{\#}$ & $6.3(5.1-8.3)^{\#,+}$ \\
\hline $2.4(1.1-4.9)$ & $1.5(0.5-3.6)$ & $2.6(1.2-5.2)^{\#}$ & $3.7(1.9-5.7)^{\#,+}$ \\
\hline $6.5(2.7-12.7)$ & $2.1(0.9-3.4)$ & $7.0(6.0-8.5)^{\#}$ & $13.9(12.0-16.4)^{\#,+}$ \\
\hline $3.5(1.0-8.6)$ & $1.2(0-2.6)$ & $5.0(2.2-7.2)^{\#}$ & $10.0(5.5-13.6)^{\#,+}$ \\
\hline $10.6(3.0-24.1)$ & $2.7(0-5.9)$ & $10.6(7.0-20.5)^{\#}$ & $22.3(15.2-35.1)^{\#,+}$ \\
\hline $4.4(2.2-7.0)$ & $2.0(1.0-4.4)$ & $4.2(2.7-6.2)$ & $6.2(4.5-8.2)^{\#,+}$ \\
\hline $2.1 \pm 11.1$ & $1.1 \pm 7.5$ & $1.5 \pm 10.1$ & $2.9 \pm 14.3^{\#,+}$ \\
\hline $6.0(3.0-9.0)$ & $6.0(3.0-8.0)$ & $5.0(3.0-9.0)$ & $5.0(3.5-8.5)$ \\
\hline
\end{tabular}

$\begin{array}{cc}95(9.1) & \\ 56(58.9) & <0.0001 \\ 55.0(47.2-66.1)^{\#} & <0.0001 \\ 26.3(23.6-30.4)^{\#, 9,+} & <0.0001 \\ 0.92(0.87-0.97)^{\#,++} & <0.0001 \\ 36.0(34.4-39.0)^{\#,+} & <\mathbf{0 . 0 0 0 1} \\ 40(42.1)^{\#} & <\mathbf{0 . 0 0 0 1} \\ 11(11.6)^{\#} & \mathbf{0 . 0 0 1} \\ 187(17.9)^{\#} & <\mathbf{0 . 0 0 0 1} \\ 5(6.3) & 0.887 \\ 27(28.4)^{\#} & \mathbf{0 . 0 0 1} \\ 1(1.1) & 0.058 \\ 13(13.8)^{\#} & \mathbf{0 . 0 4 5} \\ 22(23.2)^{\#,+} & 0.858 \\ 0.41 \pm 0.78 & 0.511 \\ & \\ 5.6 \pm 6.7 & 0.497 \\ 391.5(353.0- & \mathbf{0 . 0 0 2} \\ 420.4)^{\#, 9,+} & \\ 131.2(47.0-189.1) & 0.111 \\ 27.8(6.0-57.5) & 0.062 \\ 20.4(17.0-23.6)^{\#, 9,+} & <\mathbf{0 . 0 0 0 1} \\ 22.3(18.0-26.1) & 0.237 \\ 15.7(12.0-21.6)^{\#} & <\mathbf{0 . 0 0 0 1} \\ 8.1(6.9-9.2)^{\#, 9,+} & <\mathbf{0 . 0 0 0 1} \\ 3.2(2.0-4.2)^{\#} & <\mathbf{0 . 0 0 0 1} \\ 24.7(21.7-28.3)^{\#, 9,+} & <\mathbf{0 . 0 0 0 1} \\ 20.5(7.0-26.4)^{\#, 9,+} & <\mathbf{0 . 0 0 0 1} \\ & \\ 31.8(25.8-46.0)^{\#, 9,+} & <\mathbf{0 . 0 0 0 1} \\ 8.4(6.9-10.2)^{\#, 9,+} & <\mathbf{0 . 0 0 0 1} \\ 5.6 \pm 15.7^{\#, 9,+} & <\mathbf{0 . 0 0 0 1} \\ 6.0(3.0-9.0) & 0.906\end{array}$

Data are presented as $\mathrm{n}(\%)$, median (interquartile range) or mean \pm SD, unless otherwise stated. Data was analysed by Pearson's Chi-squared test or by the Kruskal-Wallis test, followed by Mann-Whitney pairwise comparisons. The number of participants with missing data was as follows: alcohol consumption before PSG ( $n=19)$, antidepressant medication ( $n=27)$, benzodiazepines $(n=15), B M I(n=3)$, smoking ( $n=7)$, depression ( $n=169)$, neck circumference ( $n=33)$, NREM-AHI supine ( $n=58)$, REM-AHI supine ( $n=194), T 90$ ( $n=12)$, WHR ( $n=1)$. Values in bold indicate significant results ( $p<0.05$ ). BMI: body mass index; WHR: waist-to-hip ratio; PSG: polysomnography; TST: total sleep time; SWS: slow wave sleep; NREM: non-rapid eye movement; ODI: oxygen desaturation index (number of $3 \%$ or greater oxygen desaturations per hour); T90: percentage of TST with oxygen saturation below 90\%; ESS: Epworth Sleepiness Scale. ${ }^{\#}$ : $p<0.008$ compared to $<5$ events.h ${ }^{-1}$; ${ }^{\uparrow}: p<0.008$ compared to $10-19.9$ events $\cdot \mathrm{h}^{-1} ;{ }^{+}: \mathrm{p}<0.008$ compared to $5-9.9$ events $\cdot \mathrm{h}^{-1}$; ${ }^{\S}$ : alcohol consumption=mean consumption of standard drinks containing $10 \mathrm{~g}$ of alcohol.

both genders in our analysis. However, this is unlikely to explain the lack of association we found because our models were also negative when we restricted the analysis to men (data not shown). The analysis on the Wisconsin cohort by Mokhlesi and colleagues used 24-h BP monitoring while we used three measurements in the morning. Although this is a potential source of difference between the two studies, the MAILES study used the same technique as in the present study and found a significant association between REM-SDB and hypertension. When using BP as a continuous dependent variable there was, however, a significant positive association between moderate-to-severe REM-AHI and both systolic and diastolic BP. These findings appear to suggest a possible positive association between REM-SDB and BP.

\section{REM-SDB and depression}

We did not find a significant association between depression and REM-SDB besides a trend in the NREM-AHI $<10$ events.h ${ }^{-1}$ subgroup. Our group and others have previously shown that patients with 


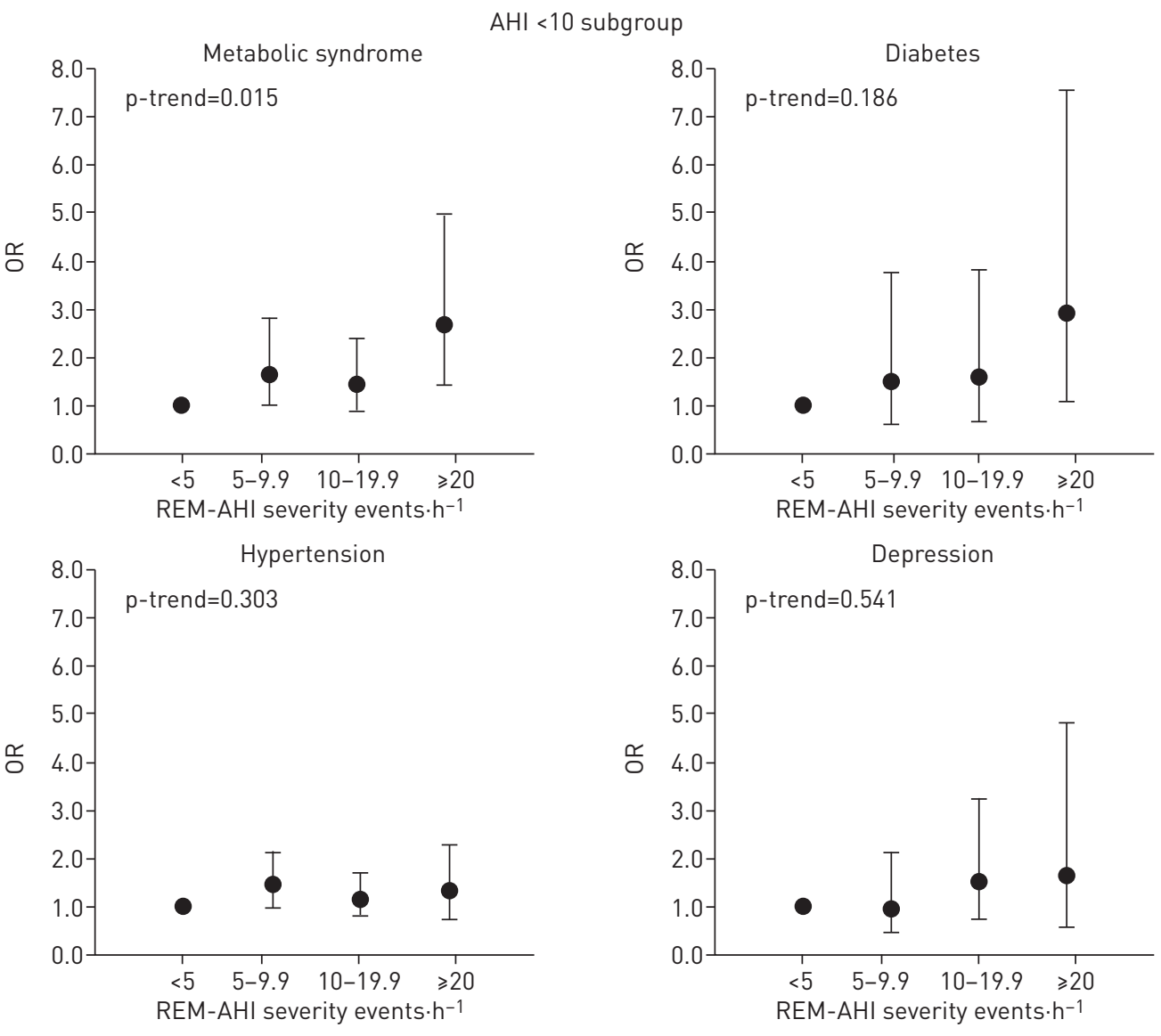

FIGURE 3 Odds ratios (ORs) and $95 \% \mathrm{Cls}$ for rapid eye movement (REM) apnoea-hypopnoea index (AHI) severity categories (REM-AHI severity) in the subgroup with total AHI $<10$ events $\cdot \mathrm{h}^{-1}$ ( $\mathrm{n}=1047$ polysomnographies (PSGs)). Circles represent the ORs and bars represent the $95 \%$ Cls. Logistic regression models were fitted to examine the associations for the entire cohort with metabolic syndrome, diabetes, hypertension and depression. Moderate-to-severe REM related sleep-disordered breathing (REM-SDB) was significantly associated with metabolic syndrome and diabetes. Diabetes, hypertension and depression showed no association with REM-SDB. Cardiovascular and metabolic comorbidities were adjusted for age, sex, body mass index, waist-to-hip ratio, total sleep time, smoking, alcohol consumption (weekly) and the logarithm of non-REM-AHI (log-NREM-AHI). Depression was adjusted for age, gender, consumption of benzodiazepines, antidepressants and log-NREM-AHI. The number of participants with missing data in the models was as follows: metabolic syndrome $(n=11)$, diabetes $(n=11)$, hypertension $(n=11)$, depression $(n=189)$.

SDB are at higher risk of depressive disorders [1, 42-44] and have a greater prevalence of other psychiatric comorbidities [45-47]. However, the mechanisms underlying the possible association between REM-SDB and depression are not clear. Oxygen desaturation and hypoxia during sleep have been proposed as potential mechanisms for this association because interventional studies using oxygen or CPAP therapies $[48,49]$ found that reversing hypoxaemia in SDB improved mood disorders. Moreover, due to its likely role in emotion processing, REM sleep fragmentation could have a negative impact on mood [50]. However, we did not find an independent association of depression with ODI, T90 or arousal index (data not shown).

\section{Strengths and limitations}

The main strength of this study is the inclusion of a large sample representative of the general population and the extensive phenotyping of participants, which allowed the creation of models controlling for the main confounding factors for each analysed outcome. However, our study also has limitations that need to be acknowledged. First, the cross-sectional design does not allow any causality relationships to be determined. Secondly, the study population was aged between 40 and 85 years and essentially of white European origin with a low prevalence of obesity. Thus, generalizability of our findings to younger, more obese populations of different ethnicity is not possible. Lastly, we did not use the dichotomised definition of REM-SDB proposed by others [2-4]. However, we believe that the use of REM-AHI severity categories allows more precise analysis than a dichotomous classification. 
In conclusion, our findings show that moderate-to-severe REM-SDB is highly prevalent in the general population, even in individuals classified as having absent or mild SDB, and that REM-SDB is independently associated with important cardiovascular risk factors such as metabolic syndrome and diabetes. As CPAP use is often limited to the first part of the night, leaving most REM-SDB untreated, our results strengthen the concept that patients should be encouraged to use CPAP for the whole night to obtain maximum benefit.

Acknowledgements: The authors would like to thank Prof. M. Tafti (Physiology Department, University of Lausanne, Switzerland) for his contribution to the HypnoLaus study.

Conflict of interest: M. Preisig reports unrestricted research grants from the Swiss National Science Foundation and GlaxoSmithKline, during the conduct of the study. P. Vollenweider reports an unrestricted grant to build the CoLaus cohort, from GlaxoSmithKline, during the conduct of the study. R. Heinzer reports grants from the Swiss National Science Foundation (grants 3200B0-105993, 3200B0-118308, 33CSCO-122661, 33CS30-139468 and 33CS30-148401), the Leenaards Foundation, the Ligue Pulmonaire Vaudoise, GlaxoSmithKline and the Faculty of Biology and Medicine of Lausanne University, during the conduct of the study; and personal fees for medical advisory board work from Nightbalance, outside the submitted work.

Support statement: The Faculty of Biology and Medicine of Lausanne University, the Lausanne University Hospital (CHUV), the Leenaards Foundation and the Ligue Pulmonaire Vaudoise funded the salary of the technicians who did the sleep recordings. The Swiss National Science Foundation funded the statisticians and supported the initial CoLaus/ PsyCoLaus cohort. GlaxoSmithKline supported the initial CoLaus/PsyCoLaus cohort and funded the polysomnography recorders. The funders of the study had no role in study design, data collection, data analysis, data interpretation, or writing of the report. The corresponding author had full access to all data in the study and had final responsibility for the decision to submit for publication. Funding information for this article has been deposited with the Crossref Funder Registry.

\section{References}

1 Heinzer R, Vat S, Marques-Vidal P, et al. Prevalence of sleep-disordered breathing in the general population: the HypnoLaus study. Lancet Respir Med 2015; 3: 310-318.

2 Conwell W, Patel B, Doeing D, et al. Prevalence, clinical features, and CPAP adherence in REM-related sleep-disordered breathing: a cross-sectional analysis of a large clinical population. Sleep Breath 2012; 16: 519-526.

3 Haba-Rubio J, Janssens JP, Rochat T, et al. Rapid eye movement-related disordered breathing: clinical and polysomnographic features. Chest 2005; 128: 3350-3357.

4 Koo BB, Patel SR, Strohl K, et al. Rapid eye movement-related sleep-disordered breathing: influence of age and gender. Chest 2008; 134: 1156-1161.

5 Pamidi S, Knutson KL, Ghods F, et al. Depressive symptoms and obesity as predictors of sleepiness and quality of life in patients with REM-related obstructive sleep apnea: cross-sectional analysis of a large clinical population. Sleep Med 2011; 12: 827-831.

6 Chami HA, Baldwin CM, Silverman A, et al. Sleepiness, quality of life, and sleep maintenance in REM versus non-REM sleep-disordered breathing. Am J Respir Crit Care Med 2010; 181: 997-1002.

7 Punjabi NM, Bandeen-Roche K, Marx JJ, et al. The association between daytime sleepiness and sleep-disordered breathing in NREM and REM sleep. Sleep 2002; 25: 307-314.

8 Khan A, Harrison SL, Kezirian EJ, et al. Obstructive sleep apnea during rapid eye movement sleep, daytime sleepiness, and quality of life in older men in Osteoporotic Fractures in Men (MrOS) Sleep Study. J Clin Sleep Med 2013; 9: 191-198.

9 Krieger J, Sforza E, Boudewijns A, et al. Respiratory effort during obstructive sleep apnea: role of age and sleep state. Chest 1997; 112: 875-884

10 Findley LJ, Wilhoit SC, Suratt PM. Apnea duration and hypoxemia during REM sleep in patients with obstructive sleep apnea. Chest 1985; 87: 432-436.

11 Peppard PE, Ward NR, Morrell MJ. The impact of obesity on oxygen desaturation during sleep-disordered breathing. Am J Respir Crit Care Med 2009; 180: 788-793.

12 Shea SA, Edwards JK, White DP. Effect of wake-sleep transitions and rapid eye movement sleep on pharyngeal muscle response to negative pressure in humans. J Physiol 1999; 520: 897-908.

13 McSharry DG, Saboisky JP, Deyoung P, et al. Physiological mechanisms of upper airway hypotonia during REM sleep. Sleep 2014; 37: 561-569.

14 Kohler M, Stradling JR. CrossTalk proposal: most of the cardiovascular consequences of OSA are due to increased sympathetic activity. J Physiol 2012; 590: 2813-2815. Discussion 2823.

15 Somers VK, Dyken ME, Clary MP, et al. Sympathetic neural mechanisms in obstructive sleep apnea. J Clin Invest 1995; 96: 1897-1904.

16 Somers VK, Dyken ME, Mark AL, et al. Sympathetic-nerve activity during sleep in normal subjects. $N$ Engl J Med 1993; 328: 303-307.

17 Trinder J, Kleiman J, Carrington M, et al. Autonomic activity during human sleep as a function of time and sleep stage. J Sleep Res 2001; 10: 253-264.

18 Mokhlesi B, Finn LA, Hagen EW, et al. Obstructive sleep apnea during REM sleep and hypertension. results of the Wisconsin Sleep Cohort. Am J Respir Crit Care Med 2014; 190: 1158-1167.

19 Appleton SL, Vakulin A, Martin SA, et al. Hypertension is associated with undiagnosed OSA during rapid eye movement sleep. Chest 2016; 150: 495-505.

20 Mokhlesi B, Hagen EW, Finn LA, et al. Obstructive sleep apnoea during REM sleep and incident non-dipping of nocturnal blood pressure: a longitudinal analysis of the Wisconsin Sleep Cohort. Thorax 2015; 70: 1062-1069.

21 Grimaldi D, Beccuti G, Touma C, et al. Association of obstructive sleep apnea in rapid eye movement sleep with reduced glycemic control in type 2 diabetes: therapeutic implications. Diabetes Care 2014; 37: 355-363. 
22 Chami HA, Gottlieb DJ, Redline S, et al. Association between glucose metabolism and sleep-disordered breathing during REM sleep. Am J Respir Crit Care Med 2015; 192: 1118-1126.

23 Firmann M, Mayor V, Vidal PM, et al. The CoLaus study: a population-based study to investigate the epidemiology and genetic determinants of cardiovascular risk factors and metabolic syndrome. BMC Cardiovasc Disord 2008; 8: 6 .

24 Preisig M, Waeber G, Vollenweider P, et al. The PsyCoLaus study: methodology and characteristics of the sample of a population-based survey on psychiatric disorders and their association with genetic and cardiovascular risk factors. BMC Psychiatry 2009; 9: 9.

25 Johns MW. A new method for measuring daytime sleepiness: the Epworth sleepiness scale. Sleep 1991; 14: $540-545$

26 Iber C, Ancoli-Israel S, Chesson A, et al. The AASM Manual for the scoring of sleep and associated events: rules, terminology and technical specifications. 1st Edn. Westchester, IL, American Academy of Sleep Medicine, 2007.

27 Berry RB, Budhiraja R, Gottlieb DJ, et al. Rules for scoring respiratory events in sleep: update of the 2007 AASM Manual for the Scoring of Sleep and Associated Events. Deliberations of the Sleep Apnea Definitions Task Force of the American Academy of Sleep Medicine. J Clin Sleep Med 2012; 8: 597-619.

28 National Cholesterol Education Program (NCEP) Expert Panel on Detection, Evaluation, and Treatment of High Blood Cholesterol in Adults (Adult Treatment Panel III). Third Report of the National Cholesterol Education Program (NCEP) Expert Panel on Detection, Evaluation, and Treatment of High Blood Cholesterol in Adults (Adult Treatment Panel III) final report. Circulation 2002; 106: 3143-3421.

29 Trull TJ, Verges A, Wood PK, et al. The structure of Diagnostic and Statistical Manual of Mental Disorders (4th edition, text revision) personality disorder symptoms in a large national sample. Personal Disord 2012; 3: 355-369.

30 Coughlin SR, Mawdsley L, Mugarza JA, et al. Obstructive sleep apnoea is independently associated with an increased prevalence of metabolic syndrome. Eur Heart J 2004; 25: 735-741.

31 Gruber A, Horwood F, Sithole J, et al. Obstructive sleep apnoea is independently associated with the metabolic syndrome but not insulin resistance state. Cardiovasc Diabetol 2006; 5: 22.

32 Mokhlesi B, Grimaldi D, Beccuti G, et al. Effect of one week of 8-hour nightly continuous positive airway pressure treatment of obstructive sleep apnea on glycemic control in Type 2 diabetes: a proof-of-concept study. Am J Respir Crit Care Med 2016; 194: 516-519.

33 Shaw JE, Punjabi NM, Naughton MT, et al. The effect of treatment of obstructive sleep apnea on glycemic control in Type 2 diabetes. Am J Respir Crit Care Med 2016; 194: 486-492.

34 McEvoy RD, Antic NA, Heeley E, et al. CPAP for prevention of cardiovascular events in obstructive sleep apnea. N Engl J Med 2016; 375: 919-931.

35 Louis M, Punjabi NM. Effects of acute intermittent hypoxia on glucose metabolism in awake healthy volunteers. J Appl Physiol (1985) 2009; 106: 1538-1544.

36 Bloom SR, Edwards AV, Hardy RN. The role of the autonomic nervous system in the control of glucagon, insulin and pancreatic polypeptide release from the pancreas. J Physiol 1978; 280: 9-23.

37 Lembo G, Capaldo B, Rendina V, et al. Acute noradrenergic activation induces insulin resistance in human skeletal muscle. Am J Physiol 1994; 266: E242-E247.

38 Nonogaki K. New insights into sympathetic regulation of glucose and fat metabolism. Diabetologia 2000; 43: 533-549.

39 Bialasiewicz P, Czupryniak L, Pawlowski M, et al. Sleep disordered breathing in REM sleep reverses the downward trend in glucose concentration. Sleep Med 2011; 12: 76-82.

40 Fendri S, Rose D, Myambu S, et al. Nocturnal hyperglycaemia in type 2 diabetes with sleep apnoea syndrome. Diabetes Res Clin Pract 2011; 91: e21-e23.

41 Peppard PE, Young T, Palta M, et al. Prospective study of the association between sleep-disordered breathing and hypertension. N Engl J Med 2000; 342: 1378-1384.

42 Peppard PE, Szklo-Coxe M, Hla KM, et al. Longitudinal association of sleep-related breathing disorder and depression. Arch Intern Med 2006; 166: 1709-1715.

43 Chen YH, Keller JK, Kang JH, et al. Obstructive sleep apnea and the subsequent risk of depressive disorder: a population-based follow-up study. J Clin Sleep Med 2013; 9: 417-423.

$44 \mathrm{Lu}$ MK, Tan HP, Tsai IN, et al. Sleep apnea is associated with an increased risk of mood disorders: a population-based cohort study. Sleep Breath 2017; 21: 243-253.

45 Baran AS, Richert AC. Obstructive sleep apnea and depression. CNS Spectr 2003; 8: 128-134.

46 Sharafkhaneh A, Giray N, Richardson P, et al. Association of psychiatric disorders and sleep apnea in a large cohort. Sleep 2005; 28: 1405-1411.

47 Lin WC, Winkelman JW. Obstructive sleep apnea and severe mental illness: evolution and consequences. Curr Psychiatr Rep 2012; 14: 503-510.

48 Derderian SS, Bridenbaugh RH, Rajagopal KR. Neuropsychologic symptoms in obstructive sleep apnea improve after treatment with nasal continuous positive airway pressure. Chest 1988; 94: 1023-1027.

49 Bardwell WA, Norman D, Ancoli-Israel S, et al. Effects of 2-week nocturnal oxygen supplementation and continuous positive airway pressure treatment on psychological symptoms in patients with obstructive sleep apnea: a randomized placebo-controlled study. Behav Sleep Med 2007; 5: 21-38.

50 Duncan WC Jr, Pettigrew KD, Gillin JC. REM architecture changes in bipolar and unipolar depression. Am J Psychiatry 1979; 136: 1424-1427. 